\title{
A CONCEPÇÃO DE PRÁTICA SOCIAL POR MEIO DA APROPRIAÇÃO DE GÊNEROS DISCURSIVOS EM DOCUMENTOS NACIONAIS: DOS PCN À BNCC
}

\section{THE CONCEPTION OF SOCIAL PRACTICE THROUGH THE APPROPRIATION OF DISCURSIVE GENRES IN NATIONAL DOCUMENTS: FROM PCN TO BNCC}

\author{
Luiz Eduardo Mendes Batista*
}

\begin{abstract}
Resumo: Este artigo objetiva analisar a noção de prática social no ensino de língua portuguesa por meio da apropriação de gêneros discursivos, como definidos por Mikhail Bakhtin, na trajetória de construção de documentos curriculares no Brasil, especialmente os Parâmetros Curriculares Nacionais - PCN -, de 1998, e a Base Nacional Comum Curricular, de 2017. Entendemos que uma proposta de ensinoaprendizagem de língua que propicie uma efetiva participação social democrática dos alunos nas diversas esferas de atividade considera os gêneros como objeto central. De modo geral, os documentos apresentam problemas de tratamento dado aos gêneros, como a bricolagem de conceitos como texto, gênero e tipo, especialmente nos PCN, e uma centralização inflexível da proposta de trabalho com gêneros a partir da progressão de aprendizagens, na BNCC, desafiando pesquisadores e professores a uma revisão crítica desses documentos.
\end{abstract}

Palavras-chave: Prática social. Gênero discursivo. Documentos curriculares nacionais.

\begin{abstract}
This paper aims to analyze the notion of social practice in Portuguese language teaching through the appropriation of discursive genres, according to Mikhail Bakhtin, in the construction and validation of curricular documents in Brazil, especially the Parâmetros Curriculares Nacionais - PCN, 1998, and the Base Nacional Comum Curricular - BNCC, 2017. We believe that a teaching-learning proposal of language that provides an effective emancipatory social participation and, therefore, democratic, of the students in the diverse spheres of human activity considers the genres as central object. In general, the documents present problems of conception and treatment given to the genres, such as the mere bricolage of complex concepts like text, genre and type, especially in PCN, and an inflexible centralization of the proposal of work with genres from the progression of learning, mainly at the BNCC, challenging researchers and teachers to a critical review of these documents, avoiding its simple transposition.
\end{abstract}

Keywords: Social practice. Discursive genre. National curriculum documents.

\section{Introdução}

O presente artigo situa-se, de modo geral, no âmbito das atuais discussões no campo dos estudos linguísticos que visam a investigar o ensino de língua portuguesa, especialmente quando este pretende assimilar reflexivamente contextos diversos que dialogam com a esfera escolar. Mais especificamente, nosso objetivo principal é analisar o modo como a ideia de prática social no ensino de língua portuguesa emerge e é defendida nos documentos curriculares nacionais, compreendendo aqueles situados no período de redemocratização do Brasil, pós-promulgação da Constituição de 1988, a saber: os Parâmetros Curriculares Nacionais, PCN, em 1998, e a Base Nacional Comum Curricular, BNCC, em 2017, passando, quando necessário, pelas Diretrizes Curriculares Nacionais, DCN, publicadas em 2013.

\footnotetext{
* Doutorando do Programa de Pós-Graduação em Estudos Linguísticos da Universidade Federal de Uberlândia - UFU (2018). Possui graduação (2005) e Mestrado em Linguística pela UFU (2008). Realiza pesquisas na área de ensino-aprendizagem de língua materna (portuguesa), bem como na área de gêneros discursivos, tipologia textual, coesão e coerência textuais, com base nos pressupostos da Linguística de Texto e da Linguística Aplicada. Atualmente, é professor efetivo de Língua Portuguesa da Secretaria de Educação do Distrito Federal. luizedumb@yahoo.com.br
} 
Uma vez que compreendemos esses parâmetros curriculares como ações políticas voltadas ao ensino, utilizaremos a noção de ciclos de políticas educacionais, conforme proposto incialmente por Stephen Ball e sintetizado por Mainardes (2006), que propõe como sendo três os principais contextos de concretização dos ciclos de políticas: o contexto de influência, em que se identificam as instâncias influenciadoras do surgimento de políticas públicas, como o Conselho Nacional de Educação, CNE; o contexto de produção de textos, composto pela materialidade textual proposta por essas instâncias políticas, como os documentos curriculares, as leis etc., e o contexto da prática, que corresponde à apropriação e ao jogo de inferências, transformado os contextos anteriores em ações/ atitudes, propriamente ditas, para as quais as políticas foram criadas. Neste último caso, refere-se, no que diz respeito ao ensino, ao modo como se dão as práticas pedagógicas dos professores, por exemplo. Por serem vistos como um ciclo, e não de modo linear, os três contextos podem inter-relacionar, porém, no caso deste estudo, nos situamos no contexto específico da produção de textos, dado nosso empreendimento em analisar os documentos apresentados acima.

Para cumprir nosso objetivo, acreditamos ser necessário expor, primeiramente, como se deu a inscrição do social nos estudos linguísticos a partir do século XX, principalmente por meio de Labov (2008 [1972]), que reconheceu o estatuto dinâmico da língua, passando a investigá-la não mais de modo abstrato, mas apenas a partir de dados concretos onde ela se realiza, e Bakhtin (2006 [1979]), que defendeu o caráter comunicativo e dialógico da linguagem humana ao introduzir a noção de gêneros do discurso. Essa noção, por sua vez, é a que melhor catalisa a ideia de prática ou participação social por meio do uso da língua. Nessas estruturas discursivas, os elementos linguístico e social aparecem imbricados, por isso, é impossível tratar os gêneros discursivos sem considerar, antes de tudo, sua ancoragem histórico-social, sua circulação em dada esfera da atividade humana, conforme propôs o autor russo.

Ao analisarmos documentos curriculares nacionais que se afirmam democráticos, justamente por acreditarem promover a participação cidadã dos envolvidos, não pudemos nos furtar à verificação crítica desse estatuto em nosso corpus, por meio do conceito de emancipação intelectual na educação, desenvolvido por Rancière (2011). Por um lado, é importante registrar que partimos do pressuposto de que a apropriação dos gêneros discursivos no ensino de língua vai ao encontro dessa ideia de se crer que a escola deve ser um espaço de participação democrática. Por outro, essa investigação dos documentos nos permitiu uma visão mais ampla do modo com eles surgiram e se tornaram parâmetros para se (re)pensar tal espaço.

Em seguida, nos dois últimos itens, partimos para a análise dos PCN e da BNCC, propriamente ditas. De modo geral, a situação conflituosa e, por que não dizer, instável pela qual têm passado as diversas instituições brasileiras, em especial a escola pública, o presente estudo pode ser relevante por buscar um debate que nos leve a (re)examinar concepções teórico-metodológicas, aspectos da (auto)formação inicial e continuada e, consequentemente, o exercício docente.

\section{A emergência do social nos estudos linguísticos em Labov e em Bakhtin}

Antes de passarmos à análise dos documentos curriculares surgidos após a redemocratização no Brasil, marcada pela promulgação da Constituição de 1988, importa-nos recuperar um debate importante travado pelas teorias linguísticas do século XX sobre a emergência e recepção do aspecto social nos estudos linguísticos.

Como se sabe, esse debate tem início com as discussões saussurianas no contexto de compreensão e validação da Linguística enquanto ciência. Para Saussure, o 
estudo da língua, objeto da Linguística, leva em conta a ideia de que esta se trata de um sistema presente na mente dos falantes. Por ser um sistema dado a priori, os falantes compreendem um ao outro, possibilitando sua comunicação. Essa visão saussureana de interação encontra uma definição um pouco mais clara na expressão "massa falante" (cf. COLOMBAT et al., 2017), momento em que o autor reconhece que para que a língua exista, faz-se necessário uma massa de falantes que a usem. Ressalvadas as intenções plausíveis de Saussure que se inserem em um momento histórico de rompimento com as correntes históricas e comparatistas do século XIX, não assumimos essa visão estreita de interação social e de língua. Recorremos a outras vertentes dos estudos linguísticos e da linguagem - amplamente divulgadas por William Labov, (socio)linguista estadounidense, e por Mikhail Bakhtin, estudioso russo de questões da linguagem humana, ambos tendo desenvolvido seus estudos na segunda metade do século XX.

Fazendo frente direta a Saussure, Labov enxerga nas formulações do linguista francês sobre a língua e seus falantes uma contradição, que ele vai denominar de paradoxo saussuriano. Ou seja, como é possível afirmar que a língua só existe por haver um contrato entre os falantes e se exclui o aspecto social como fator necessário da pesquisa linguística?

Esse questionamento insere-se na problematização suscitada pelo autor que altera o ponto de vista sobre o objeto linguístico. Ora, se estamos tratando de um objeto, a língua, utilizado por falantes reais em dado contexto, é óbvia a relação entre língua e interação/prática social. O posicionamento de Labov em relação aos estudos saussurianos, e também aos estudos do gerativista Noam Chomsky, não desmereceu muito menos pretendeu criar uma nova ciência em oposição direta à Linguística. $\mathrm{O}$ próprio autor, na introdução de sua obra (LABOV, 2008 [1972]), mostra resistência em usar um novo termo, sociolinguística, já que é constitutivo da língua sua ancoragem social, em que falantes reais interagem em dada comunidade de fala, atestando o tempo todo que a realidade da língua/ linguagem é sua variação, sua mudança. É interessante notar também a preocupação de Labov e seus companheiros de estudo com a questão educacional, mostrando, por exemplo, que as dificuldades de aprendizagem dos estudantes estadounidenses moradores de guetos se dão especialmente porque a escola estigmatiza seus falares, em detrimento de uma norma fabricada ao longo de séculos por grupos de prestígio social.

É partindo dessa reflexão, portanto, que aqui estamos buscando definir e adotar a noção de prática social. Restam-nos, ainda, dois elementos que precisam ser agregados a essa perspectiva que, diante de nossa intenção neste artigo, de modo central, nos conduzirão na análise dos documentos curriculares oficializados no recente período da democracia brasileira.

O primeiro elemento encontra ecos na teorização de Mikhail Bakhtin a respeito do conceito de gêneros do discurso, em sua obra "Estética da criação verbal" (BAKHTIN, 2006 [1979]), lançada mais ou menos na mesma época em que foi lançada o livro de Labov, "Padrões sociolinguísticos", nos Estados Unidos. É, no mínimo, curiosa a proximidade histórica das duas obras e, embora mereça uma reflexão mais aprofundada, cremos que as evidentes e centrais implicações sociais nos estudos desses autores estejam ligadas a uma preocupação de sua época. Sabemos que o principal vetor de forças de estudos no período se dava especialmente, no caso da Linguística, pela influência da onda estruturalista de vertentes saussuriana e chomskyana, que excluía, como dissemos, o aspecto social ou mesmo histórico de seus estudos. Assim, as ideias da sociolinguística e as reflexões bakhtinianas sobre língua, enunciado e gêneros discursivos surgem em resposta à restrição imposta pela tendência citada. 
Ao propor que o olhar do linguista deveria se voltar a dados do mundo real, em que a língua é tratada em um contexto social específico, como romances, peças teatrais, programas de televisão e rádio, Labov se distancia do modelo de pesquisa estruturalista até então vigente. Essa mudança metodológica implica para os estudos linguísticos, a adoção de gêneros discursivos ${ }^{1}$ como corpus de investigação.

Bakhtin, mesmo não sendo linguista, no sentido acadêmico-científico do termo, desenvolve uma reflexão crítica importante sobre a concepção de língua desenvolvida por Saussure, reconhecendo o emprego da língua por meio de enunciados concretos, produzidos nas esferas de atividade humana. Assim, o autor mostra que a unidade ideológica básica da língua e por meio da qual se evidenciam os conflitos humanos é a palavra (BAKHTIN 2006 [1977]) e não mais seu estrato fonético, desvinculado das intenções que atravessam essas esferas. Assim sendo, a partir da segunda metade do século XX, pode-se afirmar que a ciência linguística conheceu o lado social da língua de modo efetivo, sem excluir, vale dizer, a importância dos aspectos estruturais/ formais, mas não os tomando per si, como se nota na seguinte declaração do autor russo:

O desconhecimento da natureza do enunciado e a relação diferente com as peculiaridades das diversidades de gênero do discurso em qualquer campo da investigação linguística redundam em formalismos e em uma abstração exagerada, deformam a historicidade da investigação, debilitam as relações da língua com a vida. Ora, a língua passa a integrar a vida através de enunciados concretos (que a realizam); é igualmente através de enunciados concretos que a vida entra na língua. (BAKHTIN, 2006 [1979], p. 265).

Antes de sintetizarmos, a partir das considerações teóricas acima, a ideia aqui adotada de prática social no ensino de língua portuguesa, resta-nos trazer à luz para discussão o segundo elemento que nos guia no diálogo com as formulações labovianas e bakhtinianas: a visão democrática de ensino de língua. Em tempos em que são necessários debates e constantes discussões a respeito das contribuições dos estudos linguísticos ao ensino e, em nosso caso, ensino de língua, precisamos voltar o olhar crítico para os documentos oficiais. Estes são tomados como instrumentos situados nos ciclos das políticas de ensino - da língua - que parametrizam a elaboração de manuais didáticos e de currículos locais - em cada região e em cada escola brasileira. Vale considerar o fato de que é consenso que vivemos em um ambiente social democrático no Brasil, atestado pela Constituição de 1988, fruto de um processo histórico de redemocratização e, por sua vez, a educação é/precisa ser vista como direito assegurado/acessível a todos os cidadãos. Por essa razão, não seria novo afirmar que, do ponto de vista político, os Parâmetros Curriculares Nacionais - PCN -, lançados em 1998, e a Base Nacional Comum Curricular - BNCC -, homologada em 2017, são instrumentos que visam a direcionar/ parametrizar/ fomentar ações, tanto em nível nacional quanto local, a fim de possibilitar à população que ascenda ao saber para ter a garantia de uma participação social - prática social - efetiva, inclusiva. Obviamente, na realidade, pode não ser uma garantia alcançada por todos. Por essa razão, no ciclo de políticas (MAINARDES, 2006), a análise da produção desses documentos é uma etapa essencial para se compreender a relevância e, posteriormente, se verificarem as possibilidades pragmáticas dos mesmos.

\footnotetext{
1 O conceito de gêneros do discurso se harmoniza, em nossa percepção, com a visão de Labov, especialmente porque este autor, mesmo sem adotar o termo bakhtiniano, propõe uma virada metodológica ao dar foco aos dados reais para a investigação da língua, como mencionamos.
} 
São, portanto, esforços empreendidos pelos documentos em questão no sentido de democratizar o ensino, tornando a aprendizagem/ os saberes acessíveis aos maiores interessados, os alunos. É nessa vertente que adotamos a noção de democracia desenvolvida em Rancière (2014) e de suas reflexões sobre a educação, (RANCIÈRE, 2011), cunhando a expressão emancipação intelectual, entendida basicamente como condição principal de uma aprendizagem que se afirma democrática. Ao contestar o que chama de atual ódio da sociedade à democracia, dados constantes conflitos/ crises nela surgidos, impedindo que se crie uma "ordem" nos países que dizem tê-la como princípio, o autor defende a ideia de que tais crises são parte da democracia e não contrários a ela. Tais conflitos surgem porque a democracia se constitui de uma força que aponta para as igualdades e é em relação ao termo igualdade, tão caricaturado, que mais nos surpreendemos pelo modo sóbrio e profundamente transformador como o autor coloca:

A exigência democrática foi sustentada ou dissimulada muito tempo pela ideia de uma sociedade nova, cujos elementos seriam formados no próprio seio da sociedade atual. Foi o que o "socialismo" significou: uma visão histórica segundo a qual as formas capitalistas da produção e da troca já formavam as condições materiais de uma sociedade igualitária e de sua expansão mundial. É essa a visão que sustenta ainda hoje a esperança de um comunismo ou de uma democracia das multidões: as formas cada vez mais imateriais da produção capitalista, sua concentração no universo da comunicação formariam uma população nômade de "produtores" de um tipo novo; elas formariam uma inteligência coletiva, uma potência coletiva de pensamentos, afetos e movimentos dos corpos, capaz de explodir as barreiras do império. (RANCIÈRE, 2014, p. 121-122)

É clara a mudança de perspectiva do autor sobre o objeto em questão. Filósofo atento às questões contemporâneas, viveu, como estudante universitário, o turbulento período de 1968 na França. Sem desconsiderar princípios como o de igualdade e liberdade, abandona, como se vê na citação acima, a ideia de que a democracia é algo a ser alcançado, metafísico, em uma constante busca pelo ideal superior de soberania popular, como defendiam os principais pensadores da segunda metade do século XX, como Pierre Bourdieu, Michel Foucault e Louis Althusser, seu professor. Rancière (2014, p. 122) é categórico a respeito dessa visão ideal: "Compreender o que democracia significa é renunciar a essa fé". E, segundo o autor, para chegar a essa compreensão, há que se fazer trilhar os caminhos da emancipação intelectual, entendida na partilha da inteligência, na desconstrução da ideia de um saber superior a outro. Nesse sentido, o autor (RANCIÈRE, 2011) fará uma intensa crítica à escola que embrutece porque não dispõe o saber como algo alcançável a todos os alunos, mas rebaixa, adapta às baixas condições dos alunos que nada sabem. Assim, o autor ressignifica o sentido de igualdade, deslocando-o da mera acepção de distribuição de bens econômicos para a condição de propriedade disponível a qualquer indivíduo/ aluno. Participação ou prática social, portanto, é uma condição sine qua non da democracia, isto é, não concedemos ao outro/ aluno, não é um luxo apropriarmos dela na escola, já pertence a ele/aluno e o que nós, professores, devemos fazer é tornar evidente esse fato, de modo que cada mestre "force o aluno a usar sua própria inteligência" (RANCIÈRE, 2011, p. 34).

Assim, considerando que a construção conceitual acima é complexa pelo próprio sentido deslizante do que se entende por social - e seus correspondentes referenciais 
possíveis, como interação e contexto - cambiável de acordo com os recortes teóricos pretendidos, importa proceder a uma síntese teórica que nos direcionará na análise de como essa ideia relaciona-se ao ensino de língua portuguesa nos PCN e na BNCC, presente no item destacado a seguir. Portanto, a noção de prática social no ensino da língua materna/portuguesa é por nós considerada como:

- uma possibilidade de circulação nas diferentes esferas de atividades humanas por alunos que delas se apropriam por meio dos gêneros discursivos. Essa visão está diretamente relacionada à inscrição do aspecto social na língua, como propuseram Willian Labov, na virada metodológica que operou nos estudos linguísticos por valorizar os dados concretos de realização da língua, e Mikhail Bakhtin, que nomeia os correspondentes desses dados como gêneros do discurso. Desse modo, os alunos são compreendidos como participantes/autores e não como meros espectadores da aprendizagem da língua e, se assim são vistos, é necessário que os currículos se apropriem reflexivamente dos objetos de ensino, os gêneros.

Portanto, buscaremos verificar como aparecem abordados os gêneros, relacionados a quais aspectos da língua e da dinâmica social, de que modo são tratados e retomados, ou não, nos dois documentos oficiais, que se distanciam no tempo em duas décadas. Além disso, considerando o fato de que esses documentos surgiram em um contexto dito democrático no Brasil, em que se intenta desde então, por meio de políticas públicas, promover a participação cidadã, analisaremos o processo de emergência dos mesmos, atentando para os atores envolvidos na sua elaboração, bem como para as prováveis intenções político-pedagógicas presentes.

\section{A proposta de prática social no ensino de língua portuguesa presente nos Parâmetros Curriculares Nacionais - PCN}

Buscamos nesta seção analisar a inserção dos Parâmetros no cenário brasileiro e seu alcance democrático na educação brasileira bem como a articulação dessa análise à noção de prática social da língua materna. Utilizamos, especialmente, o documento introdutório (BRASIL, 1998a) e caderno de Língua Portuguesa referente aos Anos Finais do Ensino Fundamental (BRASIL, 1998b), por se aproximar de nossos objetivos de estudo e pesquisa. Entendemos, de qualquer forma, que o discurso presente nos PCN sobre prática social de língua seja transversal em todos os níveis da Educação Básica.

Como já mencionamos no início, o processo de investigação de políticas públicas, em nosso caso, voltado ao ensino, pressupõe três contextos que se integram, o contexto de influência, o de produção de texto e o de prática. Uma análise documental como a que estamos buscando realizar pressupõe o segundo contexto, ou seja, o do conteúdo dos textos oficiais em si.

Criado no governo de Fernando Henrique Cardoso, os Parâmetros Curriculares Nacionais expressaram o resultado de mais ou menos uma década de intensas discussões sobre os rumos da educação no Brasil após a promulgação da Constituição de 1988 e da Lei de Diretrizes e Bases da Educação Nacional (BRASIL, 1996). É importante mencionar que o documento não surgiu apenas como resultado de vontades nacionais internas, mas a partir de intensos debates em nível mundial, ocasião de participação do Brasil na Conferência Mundial de Educação para Todos, realizada em 1990 na Tailândia, convocada por órgãos como a Organização das Nações Unidas para a Educação, a Ciência e a Cultura, Unesco, e o Banco Mundial, a fim de se pensarem meios para erradicar o analfabetismo, nos países com altos índices desse problema, 
além dos sérios problemas de leitura. Assim sendo, já de início, os PCN apresentam os quatro pilares da educação baseados essencialmente no relatório da Unesco, de 1996, a saber: aprender a conhecer, aprender a fazer, aprender a viver com os outros e aprender a ser (cf. BRASIL, 1998a, p. 17).

Em termos de sua elaboração interna, os PCN incialmente foram fruto de uma investigação por técnicos e acadêmicos do Instituto Carlos Chagas a respeito dos diversos currículos publicados pelas Secretarias dos diferentes Estados brasileiros. Dessa investigação, surgiu uma proposta curricular inicial que fomentou debates em encontros e palestras a fim de se chegar à homologação do documento final em 1998.

A defesa de uma educação centrada na aprendizagem, e não no ensino, já aponta a necessidade de enxergar o aprendiz como sujeito capaz de agir socialmente, como podemos notar na Introdução:

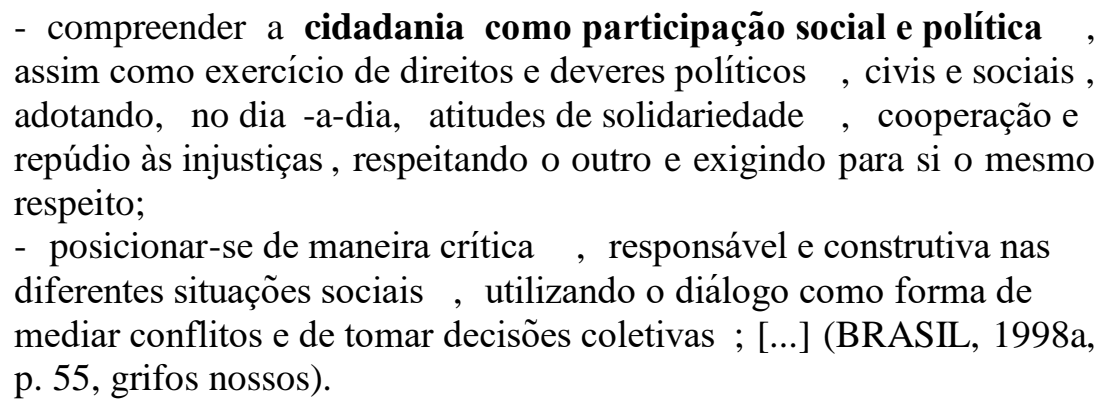

É evidente, portanto, logo nos dois primeiros objetivos apresentados para o Ensino Fundamental, que o aspecto social da aprendizagem se torna central, especialmente pela presença de termos como participação social e política, dando atenção ao posicionamento crítico e à tomada de decisões em variadas situações sociais.

O conteúdo do caderno de Língua Portuguesa, por sua vez, vai ao encontro do que menciona a Introdução aos Parâmentros, dando foco à linguagem como meio de participação social:

utilizar a linguagem na escuta e produção de textos orais e na leitura e produção de textos escritos de modo a atender a múltiplas demandas sociais, responder a diferentes propósitos comunicativos e expressivos, e considerar as diferentes condições de produção do discurso [...] (BRASIL, 1998b, p. 32).

O objetivo citado reforça a visão social de ensino de língua, destacando em desdobramentos posteriores a necessidade de se propiciar ao aluno condições de que ele desenvolva suas capacidades de realizar escolhas relacionadas ao nível de formalidade de uso da língua e ao gênero que melhor atenda a seus propósitos comunicativos. A ideia de gênero discursivo/ textual, portanto, é central nos PCN e aparece, incialmente, associada à noção de letramento, este compreendido no documento como a participação dos indivíduos em práticas sociais que se utilizam especialmente da escrita como sistema comunicativo. Embora o conceito de letramento, a nosso ver, vai além do que defendem os PCN e é, inclusive, ampliado na Base Nacional Comum Curricular, como se verá adiante, é válido reconhecer que o documento introduz, em termos de política pedagógica, já no fim do século XX, essa visão.

Se, como se percebe, os gêneros emergem no documento como um importante objeto de aprendizagem que fornece ao aluno ferramentas para agir em diversos 
contextos de letramento/ práticas sociais, é curioso observar como tal objeto, no decorrer do texto, vai agregando perspectivas distintas em sua noção que vão se sobrepondo em uma espécie de bricolagem. A partir do item Discurso e suas condições de produção, gênero e texto (BRASIL, 1998b, p. 20), as informações sobre o que os PCN compreendem por gênero se ampliam e partem, de modo evidente, da definição bakhtiniana de "tipos relativamente estáveis de enunciados" (BAKHTIN, 2006 [1979], p. 262), validados histórica e culturalmente. Nota-se, assim, uma aproximação maior das ideias do pensador russo que, na definição em sua obra, evidencia os gêneros como objetos que precisam ser considerados situados no grande tempo, isto é, no diálogo entre tempos e culturas, e não em uma linearidade temporal. Um gênero produzido em dada cultura, em outro momento, dialoga com um gênero atual e, por isso, os dois precisam ser colocados em perspectiva. É essa, em poucas palavras, a ideia de gênero como um objeto dialógico para Bakhtin; é esse um importante princípio de participação social, logo, o gênero se constitui em potencial instrumento de ensino-aprendizagem. Porém, não é essa a direção teórico-metodológica persistente nos PCN.

Após definir os gêneros, o documento aponta suas características, também evidentemente oriundas de ideias bakhtinianas, a saber: o conteúdo temático, a construção composicional e o estilo. E, justamente nesse momento, ao explicar o que considera por estilo, é inserida a noção de sequência textual, e consequentemente de tipo textual, amplamente desenvolvida por Adam (1991) e apropriada para o ensino pelos autores de Genebra, Dolz e Schneuwly (2004), sob a terminologia aspectos tipológicos. Inicia-se, portanto, um (re)direcionamento da exposição do documento para a ideia de gêneros de texto/ textuais, bem próximo do que consideram os autores suíços, em que o trabalho com o texto ganha centralidade. Daí decorrem diversas confusões entre gênero e suporte; gênero e texto; gênero e sequência e gênero e tipo textual. Em alguns momentos, os PCN situam mais ou menos adequadamente o lugar do texto, como materialidade linguística, em relação ao gênero, mas, no decorrer da construção teórica do documento, confusões começam a surgir:

- Utiliza-se texto por gênero: “os textos a serem selecionados são aqueles que, por suas características e usos, podem favorecer a reflexão crítica [...] bem como a fruição estética dos usos artísticos da linguagem, ou seja, os mais vitais para a plena participação numa sociedade letrada" (BRASIL, 1998b, p. 24) e "textos estes que se converterão, inevitavelmente, em modelos para a produção" (BRASIL, 1998b, p. 25). Ora, o que precisa ser selecionado não é o gênero, uma vez que o texto entraria como seu constituinte material? A modelização para a aprendizagem de uma produção textual voltada para a participação social não deveria advir de uma seleção de gêneros, e não de textos, que circulam na sociedade?

- Utiliza-se a ideia de tipo textual como sinônimo de gênero: ao tratar da produção textual escrita, os PCN dizem esperar que o aluno "redija diferentes tipos de textos" (BRASIL, 1998b, p. 51, grifos nossos).

Esses são apenas alguns dos problemas que deram início, desde a publicação dos Parâmetros, a inúmeras querelas entre linguistas de diferentes linhas de pesquisa e, obviamente, afetaram, e têm afetado, a formação de professores que lidam com tais ideias em sala de aula. Há, como dissemos, uma bricolagem, uma confusa sobreposição de conceitos e ideias que deveriam estar em relação com o gênero discursivo, de modo que este ganhasse centralidade enquanto objeto/ instrumento de um ensino voltado primordialmente às práticas sociais. Não haveria problema em se sugerir explorar a 
materialidade textual, mas a centralidade disso foge à ideia principal de levar o aluno à participação social, desconsidera os objetivos de ensino de língua apresentados no documento.

Em fim, a complexidade da prática social e do contexto histórico-cultural envolvidos na constituição das esferas em que circulam os gêneros escoa ao longo da elaboração do documento e toda essa complicação gerou, e tem gerado, problemas na apropriação dos gêneros em manuais didáticos, por exemplo, que servirão de apoio ao trabalho em sala de aula ${ }^{2}$.

Além desses pontos, é relevante notar, na segunda parte do caderno de Língua Portuguesa, como as sugestões de trabalho com gêneros para promover a participação social dos alunos aparecem de modo estanque e bastante questionáveis. Ao propor gêneros para serem produzidos na escola (cf. BRASIL, 1998b, p. 57), perguntamo-nos sobre a relevância para um aluno dos Anos Finais do Ensino Fundamental produzir, por exemplo, contos (ficcionais) e o que se quer dizer com produzir textos dramáticos (orais), dada a grande variedade de gêneros da esfera ficcional teatral e cinematográfica. Obviamente, como dissemos, tais gêneros surgem como propostas do documento, o que, a nosso ver, é mais problemático ainda, já que, como um documento de alcance nacional, dever-se-ia estar mais atento às escolhas que direcionam tanto a produção de materiais didáticos quanto as práticas em sala de aula. Mas como aparecem os gêneros, duas décadas após a publicação dos Parâmetros, na Base Nacional Comum Curricular? Tais problemas foram resolvidos, a fim de se definir melhor o que se compreende por prática social por meio da língua materna? É o que veremos a seguir. Antes, porém, teceremos algumas considerações que retomam a discussão inicial deste item sobre os PCN enquanto resultado de um processo democrático de ensino no Brasil.

Como apontamos, tanto em nível mundial quanto nacional, o Brasil, na década de 1990, empreende uma busca por uma democratização do ensino, prevendo a elaboração de documentos que evidenciassem, desde então, o exercício da cidadania pelos alunos promovido pela escola. Claramente, esse empreendimento está também ligado a uma preocupação de inserção do Brasil nos indicadores de educação mundial, especialmente as avaliações em larga escala como o PISA, Programa Internacional de Avaliação dos Estudantes. No entanto, como menciona Galian (2014), a assimilação dos PCN nas escolas brasileiras se deu, ou tem se dado, de modo central, quase sem sofrer as devidas reflexões e adaptações, o que demonstra uma postura pouco democrática em nível local.

Com todos os problemas mencionados, não negamos os PCN como ponto de partida para se repensar o ensino tradicional e iniciar um processo de ensino para inserção em diferentes contextos sociais, mas, dadas as deficiências em programas de formação, principalmente continuada, as ideias chegam muito mais em nível de mera transposição do que de apropriação crítica pelos professores e alunos. Além disso, o próprio modo como foi concebido, tendo, na maioria das vezes, a predominante participação de um seleto grupo de profissionais, abre caminho para se questionar o real alcance democrático do documento.

É justamente o que Rancière (2011) chama de embrutecimento, quando os principais envolvidos no processo de aprendizagem, alunos, principalmente, e professores não refletem, não questionam os saberes para a elaboração de seus currículos, mas apenas assimilam, parafraseiam, transpõem e cumprem conteúdos pré-

\footnotetext{
${ }^{2}$ Para uma ideia de como os gêneros na perspectiva dos PCN e dos autores de Genebra têm sido assimilados nos livros didáticos e alguns dos problemas que transparecem nesses manuais, diante das confusões teórico-metodológicas, sugerimos a leitura de Batista (2008).
} 
estabelecidos. Galian (2014) se questiona o quanto de fato se avançou em perspectivas sobre educação com a publicação dos $\mathrm{PCN}$ e, amparando-se em relatórios sobre o documentos e outros autores, conclui que a organização ainda centrada no ensino, e não aprendizagem, persiste, ou seja, resiste um abismo que separa as intenções de se promover uma participação social efetiva, garantida apenas quando se toma a aprendizagem como eixo principal, e a concretização de tais intenções.

Embora se mantenha a principal orientação teórica que embasa as
propostas curriculares - o que poderia ser entendido como uma opção
pela prevalência das questões relacionadas à aprendizagem e não ao
ensino -, outras permanências observadas podem nos levar a
questionar o quanto de fato se avançou, para além dos
posicionamentos teóricos e das intenções declaradas
2014, p. 661).

\section{A proposta de prática social no ensino de língua portuguesa presente na Base Nacional Comum Curricular - BNCC}

Iniciemos este item com algumas problematizações que buscaremos tratar seguindo, mais ou menos, a ordem das questões: em que contexto, dito democrático, surgiu a BNCC? Em que sentido a Base se apropria da noção de ensino e aprendizagem democráticos para propor diretrizes para uma efetiva participação social dos alunos, neste caso, dos Anos Finais do Ensino Fundamental, por meio da língua materna? E, em sentido mais específico, os gêneros discursivos são abordados como objetos centrais de uma aprendizagem para a prática social? Quais as nuances em sua abordagem teórica? Tal abordagem corresponde uma ruptura com os PCN ou uma continuidade em relação a eles?

Em relação à primeira questão, a BNCC, como está homologada e publicada (cf. BRASIL, 2017), é a terceira versão do documento oficial que contou com intensas discussões, desde 2015, ano de apresentação da primeira versão, envolvendo profissionais da educação, professores e pesquisadores acadêmicos, ligados a Instituições de Ensino Superior e a Secretarias de Educação de todas as regiões do país. Além disso, milhões de colaborações puderam ser dadas por membros da sociedade civil por um site disponibilizado anos antes da homologação final.

Como está na apresentação (BRASIL, 2017, p. 5), a Base afirma partir da Constituição Federal de 1988 e da LDB (BRASIL, 1996), reforçando a necessidade de se buscar um pacto interfederativo que não seja fechado em si, mas se constitua, como diz o nome, em uma base para a elaboração curricular dos diferentes Estados brasileiros, levando em conta as características culturais locais. Mencionam-se, então, as aprendizagens essenciais, transversais aos currículos mais locais, citando de tais leis a preocupação que já existia em se construir uma base comum dos conhecimentos ensinados. Além disso, como afirma o documento, uma base que estabelece fundamentos educacionais visa a garantir e a validar direitos de aprendizagem, em consonância com o que prevê as duas razões legais citadas.

A BNCC partiu de um projeto político de níveis mundial e nacional. Mundial, porque dialoga evidentemente com pressupostos do PISA, coordenado pela Organização para a Cooperação e Desenvolvimento Econômico - OCDE - e com as avaliações nacionais de larga escala de nível nacional, como o SAEB, o Sistema de Avaliação da Educação Básica. Por essa razão, a Base estrutura-se em competências 
gerais que definem as habilidades pontuais de cada área. Por competência, o documento entende a mobilização de conhecimentos para alcançar novas habilidades ${ }^{3}$, capacidades de realização de novas tarefas, cada vez mais complexas para agir em sociedade (remete-se à ideia de prática social).

Ainda em sua Introdução, o documento situa historicamente seu surgimento a partir das intensas discussões ocorridas no âmbito do Conselho Nacional de Educação, CNE, na década de 1990, e em seu processo de revisão, na primeira década dos anos 2000. Obviamente, não podemos negar a estrita relação da Base com os PCN, como veremos a seguir, mas é importante destacar, nesse meio tempo, o surgimento das Diretrizes Curriculares Nacionais, DCN, (BRASIL, 2013), com as quais a BNCC dialogou de modo direto. Tais Diretrizes reforçavam a educação inclusiva, a educação no campo, a biodiversidade como princípio da educação ambiental, os direitos humanos e a pluralidade e diversidade de gênero, étnico-racial etc. As DCN, portanto, configuraram um documento seminal de preparação e consolidação da Base.

Cremos que as informações acima, dado nosso propósito neste artigo de associar a ideia de documento democrático com a noção de prática social no ensino (de língua materna), são suficientes para traçarmos um panorama dessa associação e compararmos com o documento analisado anteriormente, os PCN, antes de focarmos a questão pontual de nosso estudo, a presença dos gêneros discursivos como objetos de uma proposta de ensino para a participação social.

O primeiro aspecto a que pretendemos nos referir é em relação à evidente "arena de conflitos" (COSTA, 1999) que a BNCC tem significado já em seu surgimento. Pouco antes de sua homologação e publicação em 2017, o fato de o governo da presidente Dilma Roussef sofrer impeachment provocou significativas mudanças no curso final do documento. A principal delas é referente à suspensão do grupo de profissionais na discussão e leitura crítica da terceira e última versão do documento, dissolvendo ideias que apareciam de maneira mais evidente nas duas versões anteriores do documento que dialogavam mais diretamente com as DCN, como as questões de diversidade étnico-racial e de gênero e dos direitos de aprendizagem. Não foram extintas do documento, mas foram dissolvidas, aparecendo em habilidades mais isoladas, como na habilidade EF09HI26 do componente curricular História (cf. BRASIL, 2017, p. 429), sem apresentar um posicionamento mais claro a respeito dos temas. Aparecem na Base ainda assuntos importantes para nós hoje como a questão dos movimentos migratórios mundiais e a inclusão tecnológica e digital a ser pensada e incorporada pela escola no século XXI.

Esses acontecimentos reforçam a ideia de conflito em democracia, desenvolvido por Rancière (2014), em que surgem situações críticas que, como defende o autor, não podem ser vistas de modo externo à democracia, mas como movimentos ou como vetores contrários de forças constitutivos dela. O problema é quando, diante desses conflitos, permanecemos em estado de passividade ou embrutecimento, nos impedindo a emancipação intelectual. Embora acreditemos que, ao tentar abrir a discussão não apenas para profissionais de educação, mas também para a população de modo geral, se tenha realizado algo a mais em relação à dita elaboração democrática de um documento oficial, se comparado aos PCN, percebemos certa ruptura do processo, em sua fase final, ao impedir uma análise final pelo grupo de profissionais que antes discutia a Base.

\footnotetext{
3 Em pesquisas futuras, pretendemos tratar de modo mais detido as concepções de competências, habilidades e objetivos de aprendizagem no campo dos estudos linguísticos sobre ensino de língua, visto que, a nosso ver, há problemas no modo como a Base concebe esses termos.
} 
De qualquer forma, ao lermos análises como a de Bittencourt (2017), percebemos claramente uma espécie de continuidade, mais que ruptura, em relação aos PCN, em vários aspectos. Um deles é a manutenção e ampliação na BNCC da noção de competências, além, é claro, da defesa de uma educação que prepare o aluno para o exercício da cidadania em seus diversos contextos sociais e políticos, como se apresenta nas competências em forma de objetivos para a Educação Básica, especialmente no primeiro deles:

Valorizar e utilizar os conhecimentos historicamente construídos sobre o mundo físico , social, cultural e digital para entender e explicar a realidade, continuar aprendendo e colaborar para a construção de uma sociedade justa, democrática e inclusiva. (BRASIL, 2017, p. 9).

Ainda é importante mencionar que, para Bittencourt (2017), desde o lançamento das DCN (BRASIL, 2013), o movimento do governo brasileiro tem sido no sentido de centralizar a educação brasileira, a fim de inserir-nos no contexto mais amplo da educação mundial. Para a autora, isso tem se dado mais até que no período de publicação dos PCN. Tanto o fez que as habilidades década componente curricular são identificadas por códigos alfanuméricos, um modo de organizar e facilitar a realização de avaliações em larga escala. Na verdade, nós enxergamos, como dito, uma continuidade em relação aos PCN, uma vez que neste documento, já estavam explícitos os quatro pilares da educação, citados no item anterior, desenvolvidos primeiramente em âmbito mundial.

E em relação ao instrumento gênero discursivo que, presente no ensino de língua portuguesa, pode levar o aluno à circulação nas diversas esferas de atividade humana? $\mathrm{Na}$ parte dedicada ao componente curricular Língua Portuguesa, a BNCC inicia a construção de seu conceito, situando a linguagem nas práticas sociais, fazendo, inclusive, para isso, menção aos PCN:

\footnotetext{
Assume-se aqui a perspectiva enunciativo-discursiva de linguagem, já assumida em outros documentos, como os Parâmetros Curriculares Nacionais (PCN), para os quais a linguagem é "uma forma de ação interindividual orientada para uma finalidade específica; um processo de interlocução que se realiza nas práticas sociais existentes numa sociedade, nos distintos momentos de sua história" (BRASIL, 1998, p. 20). (BRASIL, 2017, p. 65).
}

$\mathrm{Na}$ sequência, a Base assume uma centralidade no texto, enquanto unidade de trabalho, e, ainda fazendo referência aos PCN, reconhece que tal unidade entra na constituição dos gêneros discursivos/ textuais. Além disso, como é possível perceber tanto na introdução quanto em diversas habilidades da matriz de Língua Portuguesa, a ideia de variante linguística, norma-padrão, preconceito linguísticos e diversidade linguística no Brasil (línguas indígenas; línguas de imigração; de sinais, LIBRAS, oficializada como língua em 2002; crioulas e afro-brasileiras) surgem no bojo de uma discussão que visa a incluir os alunos nas diversas esferas de participação social, a fim de reduzir desigualdades.

Em seguida, o documento associa as ideias acima à de letramentos. Interessante que, na Base, essa ideia surge no plural, já que se aponta para a noção mais ampla, de multiletramentos, o que, em relação aos PCN, amplia a noção e sai do rodapé, ganhando protagonismo no corpo do texto. Evidentemente, a ideia vem intimamente relacionada à visão crítica de participação social por meio do uso da língua e abre caminho para a 
necessária inserção no espaço escolar dos atuais gêneros pertencentes às chamadas Tecnologias Digitais de Informação e Comunicação, TDIC:

As práticas de linguagem contemporâneas não só envolvem novos gêneros e textos cada vez mais multissemióticos e multimidiáticos como também novas formas de produ zir, de con gurar, de disponibilizar, de replicar e de interagir . As novas ferramentas de edição de textos, áudios, fotos, vídeos tornam a cessíveis a qualquer um a produção e disponibilização de textos multissemióticos nas redes sociais e outros ambientes da Web . Não só é possível acessar conteúdos variados em diferentes mídias , como também produzir e publicar fotos, vídeos diversos, podcasts, infográficos, enciclopédias colaborativas, revistas e livros digitais etc. Depois de ler um livro de literatura ou assistir a um filme, pode-se postar comentários em redes sociais específicas, seguir diretores, autores, escritores, acompanhar de perto seu trabalho; podemos produzir playlists, vlogs, vídeosminuto, escrever fanfics, produzir e-zines, nos tornar um booktuber, dentre outras muitas possibilidades . Em tese, a Web é democrática : todos podem acessá-la e alimentá -la continuamente. (BRASIL, 2017, p. 66).

É curioso notar que, mesmo compreendendo o valor democrático das redes sociais, a BNCC alerta para o fato de se trabalhar em perspectiva crítico-reflexiva no processo de recepção e produção desses gêneros na escola, abrindo a discussão para a questão da autoria do que se produz na Web e para a necessidade de reposicionarmos e se rediscutirmos as fronteiras entre público e privado. Além disso, alerta sobre a intensa rede de opiniões, muitas duvidosas, em detrimento de fatos observáveis, o que provoca a escola, e o professor de Língua Portuguesa para aderir ao debate dessas questões:

A viralização de conteúdos /publicações fomenta fenômenos como o da pós-verdade, em que as opiniões importam mais do que os fatos em si. Nesse contexto, torna-se menos importante checar/veri car se algo aconteceu do que simplesmente acreditar que aconteceu (já que isso vai ao encontro da própria opinião ou perspectiva ). As fronteiras entre o público e o privado estão sendo recolocadas. (BRASIL, 2107, p. 66)

O documento reconhece a novidade desses multiletramentos para a escola e aponta a necessidade de valorizá-los tanto em termos de leitura quanto de produção, por meio do contato e apropriação de recursos e gêneros como gifs, memes, vídeos-minuto, entre outros.

Por fim, antes de passar à expansão das habilidades por fase, Anos Iniciais e Anos Finais, e por anos de aprendizagem, compreendendo do $1^{\circ}$ ao $9^{\circ}$ ano, a Base delimita os quatro eixos de trabalho com a língua, a saber: o eixo da leitura, o eixo da produção de textos, o eixo da oralidade e o eixo da análise linguística/semiótica. Em todos esses eixos, o trabalho com os gêneros ganha maior atenção, considerando-os como um instrumento cultural, histórico, dialógico. Por exemplo, em relação ao eixo leitura, vejamos dois objetivos relativos à identificação das condições de elaboração dos gêneros discursivos:

- Relacionar o texto com suas condições de produção, seu contexto sócio-histórico de circulação e com os projetos de dizer : leitor e 
leitura previstos, objetivos, pontos de vista e perspectivas em jogo , papel social do autor, época, gênero do discurso e esfera/campo em questão etc.

- Analisar a circulação dos gêneros do discurso nos diferentes campos de atividade, seus usos e funções relacionados comas atividades típicas do campo, seus diferentes agentes, os interesses em jogo e as práticas de linguagem em circulação e as relações de determinaçã $\quad 0$ desses elementos sobre a construção composicional , as marcas linguísticas ligadas ao estilo e o conteúdo temático dos gêneros

(BRASIL, 2017, p. 70, grifos nossos).

Interessante observar que, diferente dos $\mathrm{PCN}$, que optam mais pelo termo gêneros textuais que gêneros discursivos, a BNCC evidencia mais o segundo uso e se afasta de perspectivas com a de Dolz e Schneuwly (2004). No entanto, ainda é possível notar, no primeiro objetivo, que o texto surge de modo central e o gênero apenas como algo a ser depreendido do texto. Em outra habilidade, em que se propõe o trabalho com a esfera jornalística nos $6^{\circ}$ e $7^{\circ}$ anos, é evidente a prioridade dada ao texto.

(EF06LP01) Reconhecer a impossibilidade de uma neutralidade absoluta no relato de fatos e identificar diferentes graus de parcialidade/ imparcialidade dados pelo recorte feito e pelos efeitos de sentido advindos de escolhas feitas pelo autor desenvolver uma atitude crítica frente aos , de forma a poder tornar-se consciente das escolhas feita (BRASIL, 2017, p.161, grifo nosso).

Ao que parece, de acordo com o que se expôs no capítulo introdutório, a intenção é levar o aluno a desenvolver habilidades de leitura de modo que ele reconheça o papel dos elementos linguísticos/ textuais e semióticos escolhidos pelo autor a fim de produzir efeitos de sentido. Não vemos, entretanto, problema algum em se realizar tal trabalho a partir dos gêneros, e não do texto, como está posto. Seria, inclusive, mais alinhado à proposta geral do documento, uma vez que tais elementos linguísticos ganhariam um estatuto mais enunciativo e seriam recolocados em função dos gêneros, com suas implicações históricas e culturais.

Além das passagens mencionadas, na introdução ao trabalho com língua portuguesa na escola, a BNCC menciona que o texto deve ser visto como o cento do trabalho pedagógico. Por que, afinal, não assumir o gênero discursivo como central? Um intercâmbio que pode produzir confusões futuras. Para o documento, os gêneros são tratados como objeto e o texto como unidade de trabalho. Essa é, no entanto, mais uma diferenciação, que também surge nos PCN, e que não nos convence como aspecto da organização do ensino de língua. Compreendemos, em acordo com os dois documentos, o texto como a materialidade que entra na constituição do gênero, mas este, definitivamente, por suas complexas características que recobrem posicionamentos intencionais e ideológicos da participação social humana, precisa ser reconhecido como objeto e unidade centrais de uma aprendizagem que visa à prática social da língua.

Analisando o segundo objetivo citado acima, acreditamos ter sido mais bem posicionado, pois dá ênfase ao trabalho com os gêneros do discurso, entendidos como instrumentos que revelam o jogo de linguagem dos interlocutores, suas escolhas discursivas e as marcas do tempo e do espaço social em sua constituição.

Em relação ao eixo produção textual, percebemos um direcionamento maior dado ao trabalho de produção que parta do gênero e não do texto: 
- Analisar as condições de produção do texto no que diz respeito ao lugar social assumido e à imagem que se pretende passar a respeito de si mesmo; ao leitor pretendido; ao veículo ou à mídia em que o texto ou produção cultural vai circular ; ao contexto imediato e ao contexto sócio-histórico mais geral ; ao gênero do discurso /campo de atividade em questão etc.

- Analisar aspectos sociodiscursivos, temáticos, composicionais e estilísticos dos gêneros propostos para a produção de textos estabelecendo relações entre eles. (BRASIL, 2017, p. 75)

Nesse sentido, ao produzir textos, reforça-se que a escola precisa partir de uma análise mais profunda da esfera de circulação do gênero, dos atores envolvidos na elaboração e leitura/escuta desse gênero, e não de sua superestrutura textual.

Outro ponto interessante que a BNCC traz é no que se refere às instâncias dessas práticas de linguagem. A título de exemplo, em relação ao eixo da produção textual, o documento separa em seis práticas : consideração e refl exão sobre as condições de produção dos textos ; dialogia e relação entre textos ; alimentação temática; construção da textualidade; aspectos notacionais e gramaticais; estratégias de produção . Desse modo, foi possível deixar mais claro, em nossa percepção, o que se pretende explorar: se as questões do gênero em si, as questões de textualidade ou mesmo de uso da variante em questão, da ortografia padrão, dentre outros. Não que esses elementos devam ser tomados de modo estanque, mas sua discriminação poderá contribuir no sentido de se compreender melhor os conceitos que lançam luz às práticas em sala de aula, sem estes apareçam sedimentados, sobrepostos, sem maiores esclarecimentos, causando inúmeras confusões nos processos de estudo e apropriação do documento curricular.

Além das práticas de linguagem, os conteúdos de língua portuguesa estão organizados na BNCC de acordo com o que chama de campo de atuação, tratado de modo sinônimo à ideia de esfera de atividade humana, como apresentada por Bakhtin (2006 [1977]). A Base elencou, para os Anos Finais, quatro campos que organizam e agrupam os gêneros a serem selecionados para a aprendizagem:

- campo artístico-literário;

- campo das práticas de estudo e pesquisa;

- campo jornalístico midiático e

- campo de atuação na vida pública.

Nos PCN, são os seguintes os campos propostos:

- literário,

- de imprensa,

- publicidade (apenas para a leitura) e

- de divulgação científica.

$\mathrm{Na}$ verdade, como mostra Marcuschi (2008), as propostas de trabalho com a leitura de gêneros nos PCN são em número maior do que com a produção de gêneros, o que, para ele, revela a pouca atenção à questão, refletindo diretamente na dificuldade em produzir textos pelos alunos quando expostos a avaliações nacionais ou locais.

Na BNCC, ao contrário, há uma proposição maior de gêneros discursivos a serem trabalhados no eixo da produção. Sempre, ao introduzir as esferas/ campos de atuação em que os alunos precisam atuar, há remissão a diversos gêneros discursivos passíveis de serem tratados na esfera em questão. O problema, como em qualquer proposta, se insere no tratamento dado à seleção escolhida, por exemplo, quando a Base 
considera como equivalentes tanto o trabalho com gêneros que circulam em esferas mais formais quanto com gêneros que circulam em esferas mais espontâneas:

Compreender uma palestra é impor tante, assim como ser capaz de atribuir diferentes sentidos a um gif ou meme. Da mesma forma que fazer uma comunicação oral adequada e sa ber produzir gifs e memes signicativos também podem sê-lo. (BRASIL, 2017, p. 67, grifos nossos)

Embora não haja um gênero melhor ou mais importante que o outro, seria um equívoco, na perspectiva de emancipação intelectual por meio da disponibilização do saber negado, dizer que gêneros como o seminário, a crítica/ resenha ou mesmo o relatório de experiências devam ser produzidos na mesma proporção que aqueles gêneros já familiarizados pelos alunos, como o meme ou o gif. Em nossa perspectiva, a participação social do aluno nas esferas mais formais de atuação, às quais este pouco ou quase nada acessa, é um elemento concebido a priori, se quisermos uma abordagem democrática e emancipatória.

Por fim, vale mencionar que na Base os conteúdos aparecem organizados em progressão de aprendizagens, do mais simples ao mais complexo. Incialmente, sugeremse gêneros e habilidades a serem explorados ao longo de toda a etapa, do $6^{\circ}$ ao $9^{\circ}$ ano, do Ensino Fundamental. Em seguida, há uma separação desses conteúdos, considerando graus de complexidade, em dois blocos, $6^{\circ}$ e $7^{\circ}$ anos e $8^{\circ}$ e $9^{\circ}$ anos. Assim sendo, no campo jornalístico, por exemplo, o documento sugere, dentre outros gêneros, a produção da notícia impressa e de resenhas críticas, no $6^{\circ} / 7^{\circ}$ ano, e de reportagem impressa e campanha publicitária, no $8^{\circ} / 9^{\circ}$ ano. Consideramos, até certo ponto, que o trabalho com a progressão didática possa corroborar com a organização dos conteúdos e competências em dado tempo de aprendizagem. Todavia, em um documento de alcance nacional, propostas tão delimitadas podem gerar problemas. Um deles reside no fato de que um gênero, a depender das características da situação particular da aprendizagem e do projeto da escola e do professor, pode ser tratado de modo mais simples ou não. No caso da notícia impressa, por exemplo, não vemos problemas no fato de que esta seja explorada no $9^{\circ}$ ano, já que, a depender das competências e características elencadas para a produção do gênero, pode não ser passível de apropriação por alunos do $6^{\circ}$ ano, diante da dificuldade que poderá ser produzir a notícia. É este, então, um aspecto que merece uma investigação mais detida em estudos futuros.

\section{Considerações finais}

Neste artigo, ficou evidente para nós a grande preocupação com a inserção das práticas sociais nos documentos que parametrizam o ensino de língua no Brasil, especialmente a partir do processo de redemocratização iniciado com a Constituição de 1988 e validado, no campo do ensino, com a publicação da LDB (BRASIL, 1996). No entanto, surgiram alguns problemas nesse processo de revisão sobre o que ensinar que demonstraram, e têm demonstrado, certa dificuldade em se instaurar um efetivo processo de participação social por meio da língua portuguesa no Brasil. Do que percebemos, destacamos os seguintes:

- A bricolagem, mera sobreposição, de conceitos e noções que geraram, e ainda geram, várias discordâncias nos espaços acadêmico e escolar, especialmente sobre em relação aos conceitos de gênero, texto e tipo 
textual. O problema é mais evidente nos PCN, embora haja alguns deslizes na BNCC, como apontamos acima;

- Diante disso, percebemos claramente, principalmente nos PCN, um gradativo abandono da ideia de gênero discursivo, de forte ancoragem social e cultural, como proposto por Bakhtin, para uma centralidade na materialidade textual em si, enfraquecendo a ideia de explorar a prática social de ensino da língua;

- A persistência dessa confusão nos documentos oficiais nacionais vem gerando problemas nos processos posteriores à publicação de tais documentos, a saber: a elaboração de materiais didáticos, a formação de professores e o próprio exercício docente em si. Daí a necessidade de se empreenderem pesquisas e estudos mais sistemáticos no espaço didático a fim de se investigar melhor a questão;

- A centralização do ensino de língua portuguesa, na BNCC, na forma de progressão de aprendizagens em que se distribuem os gêneros a serem trabalhados em dois blocos, $6^{\circ} / 7^{\circ}$ ano e $8^{\circ} / 9^{\circ}$ ano, tendo em vista uma concepção artificial de níveis de complexidade dos gêneros. A organização e seleção mais sistemática e, talvez, progressiva, dos conteúdos a serem explorados não deveria caber a um documento nacional, mas às decisões locais, tendo em vista suas características sociais e culturais. Em fim, tal centralidade vai de encontro à ideia de participação social, que pressupõe a flexibilidade das situações de aprendizagem.

De todo modo, os problemas acima só persistem ou continuarão a persistir se os documentos em questão não forem vistos unicamente como diretrizes, parâmetros, bases, e não como constituindo a palavra final das elaborações curriculares locais e das práticas de ensino e aprendizagens. $\mathrm{O}$ que de fato ameaça a perspectiva de participação social do ensino de língua materna ou de qualquer outra área do saber é a atitude passiva de professores que veem os documentos curriculares nacionais como algo a ser cumprido, transpostos ipsis litteris.

Por isso, urgem ações de formação inicial e continuada e pesquisas intensas que descentralizem as propostas teórico-metodológicas, a fim de se valorizar a participação social crítica dos envolvidos, em um movimento de emancipação intelectual.

\section{Referências}

ADAM, Jean Michel. Les textes: types et prototypes. Paris: Natan, 1992.

BAKHTIN, Mikhail. Marxismo e filosofia da linguagem. São Paulo: Hucitec, 2006 [1977).

. Os gêneros do discurso. In: BAKHTIN, M. Estética da criação verbal. São Paulo: Martins Fontes, 2006 [1979], p. 261 - 306.

BATISTA, Luiz Eduardo Mendes. Os gêneros escritos do argumentar no espaço didático. 2008. 102f. Dissertação (Mestrado em Linguística). Programa de PósGraduação em Estudos Linguísticos, Universidade Federal de Uberlândia, Uberlândia, 2008. 
BITTENCOURT, Jane. A Base Nacional Comum Curricular: uma análise a partir do ciclo de políticas. Anais do XII Congresso Nacional de Educação - EDUCERE, Curitiba, 2017, p. $553-569$.

BRASIL. Secretaria de Ensino Fundamental. Introdução aos Parâmetros Curriculares Nacionais: terceiro e quarto ciclos do ensino fundamental, Brasília, DF: MEC, 1998a.

BRASIL. Secretaria de Ensino Fundamental. Parâmetros Curriculares Nacionais de Língua Portuguesa: terceiro e quarto ciclos do ensino fundamental. Brasília, DF: MEC, 1998b.

BRASIL. Ministério de Estado da Educação. Diretrizes Curriculares Nacionais Gerais da Educação Básica, Brasília, DF, 2013.

BRASIL. Ministério de Estado da Educação. Base Nacional Comum Curricular, Brasília, DF: MEC, 2017a.

BRASIL. Lei n. 9.394, de 20 de dezembro de 1996. Lei de Diretrizes e Bases da Educação Nacional, Brasília, DF, 1996.

COLOMBAT, Bernard; PUECH, Christian; FOURNIER, Jean-Marie. Uma história das ideias linguísticas. São Paulo: Contexto, 2017.

COSTA, Marisa Vorraber. Currículo e política cultural . In: Costa, M.V. (org.). $O$ Currículo nos limiares do contemporâneo. Rio de Janeiro, DP\&A, 1999, p. 37-68.

DOLZ, Joaquim; SCHNEUWLY, Bernard et. al. Gêneros orais e escritos na escola. Campinas/SP: Mercado de Letras, 2004.

GALIAN, Cláudia V. Os PCN e a elaboração de propostas curriculares no Brasil. Cadernos de Pesquisa, São Paulo, v. 44, n. 153, p. 648-669, jul./set. 2014.

LABOV, Willian. Padrões sociolinguísticos. São Paulo: Parábola, 2008 [1972].

MAINARDES, Jefferson. Abordagem do ciclo de políticas: uma contribuição para a análise de políticas educacionais. Educação \& Sociedade, Campinas, SP, v. 27, n. 94, p. 47-69, jan./abr. 2006.

MARCUSCHI, Luiz Antônio. Produção textual, análise de gêneros e compreensão. São Paulo: Parábola, 2008.

RANCIÈRE, Jacques. $O$ mestre ignorante: cinco lições sobre a emancipação intelectual. Belo Horizonte: Autêntica, 2011. O ódio à democracia. São Paulo: Boitempo, 2014.

Recebido em 21 de setembro de 2018

Aceito em 27 de dezembro de 2018 